\title{
Environmentally adaptable pathway to emulsion polymerization for monodisperse polymer nanoparticle synthesis
}

\author{
Haruyuki Ishii, Naoto Kuwasaki, Daisuke Nagao* and Mikio Konno* \\ Department of Chemical Engineering, Graduate School of Engineering, \\ Tohoku University,
}

6-6-07 Aoba, Aramaki-aza Aoba-ku, Sendai, 980-8579 (Japan)

*Corresponding author: Mikio Konno, Prof., Daisuke Nagao, Dr.

Department of Chemical Engineering, Graduate School of Engineering, Tohoku University

6-6-07 Aoba, Aramaki-aza Aoba-ku, Sendai, 980-8579, Japan.

Tel:+81-22-795-7239, Fax: +81-22-795-7241

E-mail:konno@mickey.che.tohoku.ac.jp,nagao@mickey.che.tohoku.ac.jp 


\section{Abstract}

An environmentally adaptable method is proposed for emulsion polymerization to produce monodisperse polymer nanoparticles at surfactant concentrations much lower than conventional emulsion polymerization. The present method is based on an idea of employing a surfactant with a low critical micelle concentration (CMC) to generate a large number of polymer particles in the presence of micelles at low surfactant concentrations and to cease the particle generation by the micelle disappearance in early reaction stage for attainment of high monodispersity of particles. A hydrophobic monomer of styrene (St) and a less hydrophobic monomer of methyl methacrylate (MMA) were used in the present emulsion polymerization at a total monomer concentration of 0.3 $\mathrm{M}$ with an initiator of ammonium persulfate (APS) and a long alkyl chain surfactant of sodium octadecyl sulfate (SOS). The polymerization was conducted at a high APS concentration of $20 \mathrm{mM}$ that gave the $\mathrm{CMC}$ as low as $0.085 \mathrm{mM}$ for SOS. An increase in the monomer mole fraction of MMA increased the number of polymer particles, while the high monomer mole fraction of MMA failed to stabilize the dispersion of particles. The polymerization for a monomer ratio of $\mathrm{St} / \mathrm{MMA}=1 / 1$ could produce monodisperse polymer particles of $33 \mathrm{~nm}$ at a surfactant concentration of $1 \mathrm{mM}$ that was higher than its $\mathrm{CMC}(0.085 \mathrm{mM})$ but much lower than several ten $\mathrm{mM}$ of surfactant concentrations in conventional emulsion polymerization.

Keywords: monodisperse polymer nanoparticle; low CMC surfactant; emulsion copolymerization 


\section{Introduction}

Polymer nanoparticles have a wide variety of applications such as coating, adhesives, drug delivery, controlled release, biomedical separations and nano-structured template materials [1-8]. Since particle size is an important parameter which determines physical and chemical properties, high uniformity in particle sizes is required to regulate particle properties within a narrow range. To produce polymer nanoparticles with a narrow size distribution, various methods have been proposed [3,6,9-11]. In spite of the progress in synthetic techniques, it is still challenging to develop synthetic methods for producing small polymer particles with highly monodisperse sizes less than $100 \mathrm{~nm}$.

Emulsion polymerization is suitable for production of small particles, because micelles formed of surfactants provide the loci of particle generation [12-14]. Typical use of emulsion polymerization employs surfactant concentration much higher than the critical micelle concentration (CMC) to produce small polymer particles with high dispersion stability. However, the high surfactant concentration broadens particle size distributions. Advanced methods have been proposed for emulsion polymerization to produce small polymer particles with high monodispersity $[15,16]$. However, these production processes are not simple but multistage polymerization with the use of considerable amount of surfactants.

Polymer nanoparticles can also be produced with microemulsion polymerization [17-19] or miniemulsion polymerization [20-22]. These methods are difficult to produce highly monodisperse particles $[18,20,22]$. In addition, the methods are required to use large amount of 
surfactants and other additives such as alcohols and hydrophobes.

Surfactant-free polymerization is an environmentally adaptable process that can produce highly monodisperse polymer particles in water solvent without the addition of surfactant [23-26]. Although specific methods with extremely low monomer concentrations [8] or the use of organic cosolvent [27] can be applied to production of highly monodisperse nanoparticles in surfactant-free polymerization, production of monodisperse particles are, however, mostly limited to a particle size range of submicron-meters [28-31] to micron-meters [32-35].

Another method that restricts the use of surfactants is emulsion polymerization conducted at surfactant concentrations less than CMC. This method is applicable to the production of highly monodisperse polymer particles with small sizes [36-41]. Recently, the authors conducted the emulsion polymerization that employed a hydrophobic monomer of styrene and surfactants with low CMC under conditions of low ionic strength with an amphoteric initiator (VA-057) around neutral $\mathrm{pH}$ [41]. The use of the surfactants with low CMC was effective to produce monodisperse polymer particles less than $100 \mathrm{~nm}$ at low concentrations of submillimolar surfactant.

The present work is intended to further develop the emulsion polymerization applicable to the production of monodisperse particles less than $50 \mathrm{~nm}$. The method proposed here is schematically shown in Figure 1. Although our previous work employed styrene monomer [41], use of less hydrophobic monomer such as methyl methacrylate (MMA) is advantageous in a viewpoint of the production of large number of polymer particles due to its higher solubility in water $[42,43]$. Use of a low CMC surfactant in emulsion polymerization allows the operation at low surfactant 
concentrations, which may create an environmentally desirable process with the following merit. Since the polymerization is started in the presence of micelles that provide loci of particle generation, a large number of particles would be generated in an early stage of the polymerization but followed by deep suppression of the particle generation after the disappearance of micelles at a significantly low monomer-to-polymer conversion. This may enable production of polymer nanoparticles with a narrow size distribution. This idea is examined in the present emulsion copolymerization of St and MMA. Sodium octadecyl sulfate (SOS) is employed as a low CMC surfactant, and ammonium persulfate (APS) is used as a polymerization initiator to increase ionic strength in the system for lowering the $\mathrm{CMC}$ of the surfactant.

\section{Experimental}

Materials. Initiator (APS, 98\%), styrene (St, 99\%) and methyl methacrylate (MMA, 98\%) were obtained from Wako Pure Chemical Industries (Osaka, Japan). Anionic surfactant (SOS, 99\%) was obtained from Alfa Aesar (Ward Hill, MA, USA). St and MMA were used after removing inhibitor with an adsorption column equipment. The other chemicals were used as received. Water was deionized to have an electric resistance higher than $18 \mathrm{M} \Omega \cdot \mathrm{cm}$.

Synthesis of polymer nanoparticles. All the polymerizations were conducted in a half liter reactor with an inner diameter of $7.5 \mathrm{~cm}$. The reactor was equipped with four baffle $(0.7 \mathrm{~cm}$ in width) and four-blade-pitched paddle impeller $(5 \mathrm{~cm}$ in length) located at $1 \mathrm{~cm}$ above the bottom. Aqueous solution of SOS $(220 \mathrm{ml})$ was poured into the reactor placed in a constant temperature 
bath. The aqueous solution was bubbled with $\mathrm{N}_{2}$ gas under stirring for $30 \mathrm{~min}$. Then, monomers of St and MMA were added to the aqueous solution, which was kept stirred for 20 min under $\mathrm{N}_{2}$ atmosphere. To initiate polymerization, $30 \mathrm{ml}$ of aqueous APS solution was added into the reactor. The initial concentrations of chemicals in the polymerizations are listed in Table. Typical weights of St, MMA, SOS and APS to produce monodisperse nanoparticles were $3.9 \mathrm{~g}, 3.75 \mathrm{~g}, 9.3 \mathrm{mg}$ and $1.14 \mathrm{~g}$, respectively, for $250 \mathrm{~g}$ water, corresponding to Run 12 in the Table. The polymerizations were performed for $6 \mathrm{~h}$ at a fixed APS concentration of $20 \mathrm{mM}$ and $70{ }^{\circ} \mathrm{C}$ with stirring at $360 \mathrm{rpm}$ under $\mathrm{N}_{2}$ atmosphere.

Characterization. In each polymerization, a small amount of reaction mixture (less than 20 ml) was withdrawn from the reactor to measure particle size distribution and polymer yield. Hydroquinone was added to the reaction mixture to terminate the polymerization. The polymer yield was determined from the weight of polymer contained in the mixture with a freeze-drying method. More than 150 diameters of particles were measured with a transmission electron

$$
\begin{aligned}
& d_{\mathrm{v}}=\left(\sum n_{\mathrm{i}} d_{\mathrm{i}}^{3} / \sum n_{\mathrm{i}}\right)^{1 / 3} \\
& C_{\mathrm{V}}=\frac{\left[\sum\left\{d_{\mathrm{i}}-\left(\sum n_{\mathrm{i}} d_{\mathrm{i}} / \sum n_{\mathrm{i}}\right)\right\}^{2}\right]^{1 / 2}}{\sum n_{\mathrm{i}} d_{\mathrm{i}} / \sum n_{\mathrm{i}}} \times 100
\end{aligned}
$$

microscope (TEM mode on FE-SEM Hitachi, S-4800) to determine volume-averaged diameter, $d_{\mathrm{V}}$, and the coefficient of variation of particle size distribution, $C_{\mathrm{V}}$, defined as follows:

where $n_{\mathrm{i}}$ is the number of particles with diameter $d_{\mathrm{i}}$. Volume average diameter, $d_{\mathrm{V}}$, and a coefficient of variation of particle size distribution, $C_{\mathrm{V}}$, were calculated from the particle diameters. The 
number of particles in each polymerization, $N_{\mathrm{p}}$, was calculated from $d_{\mathrm{V}}$ and the yield. The calculated values are summarized in Table together with the chemical concentrations in the polymerization.

The CMC of SOS was measured at $70{ }^{\circ} \mathrm{C}$ with an electrical conductivity method, in which a concentrated aqueous surfactant solution SOS solution with $20 \mathrm{mM}$ APS was dropwisely added to $20 \mathrm{mM}$ APS solution and the solution conductivity was measured with a conductivity meter (D-50, Horiba Ltd., Kyoto, Japan). The CMC was determined as an inflection point of conductivity-concentration curve (Fig. S1, see supporting information). 


\section{Results and discussion}

Copolymerization of MMA and St were conducted at $[\mathrm{SOS}]=0.1 \mathrm{mM}$ in a range of MMA

mole fraction, $X_{\mathrm{MMA}}$, for a total monomer concentration of $0.3 \mathrm{M}$ on the basis of water volume.

The CMC of SOS was $0.085 \mathrm{mM}$ at the APS concentration of $20 \mathrm{mM}$ and $70{ }^{\circ} \mathrm{C}$ (see again Fig. S1).

At $X_{\mathrm{MMA}} \geqq 2 / 3$, the polymer particles coagulated at late stage of the polymerization, as shown in

Fig.2(a). Since PMMA is less hydrophobic than PSt, it is considered that the PMMA-rich particles

were not stabilized due to poor adsorption of the SOS surfactant. The poor adsorption of alkyl

sulfates to PMMA was reported by soap titrations for PSt, PMMA and their copolymer particles

$[43,44]$. The individual particles in the figure can be distinguished as spheres that have definite sizes. The $d_{\mathrm{V}}$ and $C_{\mathrm{V}}$ values of the particles, including the data of $X_{\mathrm{MMA}}=2 / 3$, are plotted in

Fig.2(b). All the $C_{\mathrm{V}}$ values measured were $<5 \%$ much lower than the typical criterion of $10 \%$

for monodispersity of particle sizes. The particle size, $d_{\mathrm{V}}$, in the St polymerization $\left(X_{\mathrm{MMA}}=0\right)$ was

large in comparison with the other data. Solubility of monomer in water solvent affects the

generation of particles. High solubility of monomer tends to promote desorption of polymer

radicals from small particles $[43,45]$, which enables new generation of particles not only in the

presence but also in the absence of micelles. Consequently, the high solubility can lead to a

decrease in particles size. On the other hand, the $C_{\mathrm{V}}$ at $X_{\mathrm{MMA}}=0$ was similar to or slightly smaller

than those at $X_{\mathrm{MMA}}>0$.

Figure 3 shows TEM images of PSt particles $\left(X_{\mathrm{MMA}}=0\right)$ in a range of [SOS] from 0.025 to 1.0

$\mathrm{mM}$. Although the St polymerization was also conducted at $[\mathrm{SOS}]=0$ and $0.01 \mathrm{mM}$, polydisperse 
particles were produced (see Fig.S2). The polydispersity implies that the particle coagulation proceeded for long period after particle generation in the polymerization. However, the surfactant addition had striking effects on particle size distributions. As shown in Fig.3, even an increase in [SOS] to $0.025 \mathrm{mM}$ generated monodisperse particles with $C_{\mathrm{V}}<10 \%$ and the monodispersity was continued up to $[\mathrm{SOS}]=0.2 \mathrm{mM}$, followed by a change in $d_{\mathrm{V}}$ from 218 to $67 \mathrm{~nm}$. The SOS concentration of $0.2 \mathrm{mM}$ is more than twice of the $\mathrm{CMC}(0.085 \mathrm{mM})$. Thus, the present work could prepare monodisperse particles at surfactant concentrations exceeding the CMC. However, the average particle size did not fall below $50 \mathrm{~nm}$. At the concentrations of $[\mathrm{SOS}] \geqq 0.4 \mathrm{mM}$, the particle sizes became polydisperse, again as seen in Fig.3.

Figure 4 shows TEM images of polymer particles in emulsion copolymerization at $X_{\mathrm{MMA}}=0.5$. In Fig.4, the particles were monodisperse in a range of [SOS] up to $1 \mathrm{mM}$ while $d_{\mathrm{V}}$ fell below $50 \mathrm{~nm}$ and attained $33 \mathrm{~nm}$ at $[\mathrm{SOS}]=1 \mathrm{mM}$ that is more than 10 times higher than the $\mathrm{CMC}(=0.085 \mathrm{mM})$. When [SOS] exceeded 1mM, particle size distribution became polydisperse.

The values of $N_{\mathrm{p}}$ and $C_{\mathrm{V}}$ obtained in the polymerizations at $X_{\mathrm{MMA}}=0$ and 0.5 are plotted against surfactant concentration, $C_{\mathrm{S}}$, in Figures 5 and 6 , respectively. The same figures contain the data obtained with a short chain length surfactant of SDS (see Fig.S3 for size distributions) of particles formed at $X_{\mathrm{MMA}}=0.5$. The CMC of SDS measured at the initiator concentration of [APS] $=20$ $\mathrm{mM}$ in water was $1.97 \mathrm{mM}$ at $70{ }^{\circ} \mathrm{C}$. Even though the $\mathrm{CMC}$ was suppressed by the high ionic concentration of APS, $1.97 \mathrm{mM}$ was almost 20 times higher than the CMC (0.085 mM) of SOS.

In Fig.5, $N_{\mathrm{p}}$ for SDS remarkably increased with an increase in $C_{\mathrm{S}}$ around the CMC. On the 
other hand, the increase in $C_{\mathrm{S}}$ around the $\mathrm{CMC}$ for SDS gave rise to the sharp increase in $C_{\mathrm{V}}$ shown in Fig.6. The tendency of $N_{\mathrm{p}}$ is the common behavior reported in the emulsion polymerizations of hydrophobic monomers with short chain length surfactants [14, 36, 39, 42,46 ]. Appearance of micelles increases the number of particles, which elongate the period of polymer particle generation, eventually resulting in an increase in $C_{\mathrm{V}}[47]$.

In Fig.5, the $N_{\mathrm{p}}$ curve of the St polymerization with SOS had a bending point clearly above its CMC. The particle formation mechanism below the CMC is expected to follow homogeneous nucleation that is polymer precipitation in the water solvent $[36,39,42,47]$. In a range of surfactant concentrations much higher than the $\mathrm{CMC}$, the formation mechanism should be the heterogeneous nucleation caused by radical entrance into micelles. Smith-Ewart theory regarding $N_{\mathrm{p}}$ vs $C_{\mathrm{S}}$ is applicable to emulsion polymerization with hydrophobic monomer such as $\mathrm{St}$. In the figure, the slope of the $N_{\mathrm{p}}$ curve above the bending point was almost consistent with 0.6 predicted by the theory. The high dependence of $N_{\mathrm{p}}$ on $C_{\mathrm{S}}$ around $\mathrm{CMC}$ is reported for the homogeneous nucleation in the polymerization of hydrophobic monomers $[14,36,39,42,46]$. For conventionally employed surfactants with a high CMC, the bending point appears on the CMC $[36,42,46]$. However, in the present case, the CMC of SOS is so small that the reduction in actual surfactant concentration in water phase, due to the surfactant adsorption on polymer particles [48], can shift the transition from the homogeneous nucleation to the heterogeneous nucleation toward the side of high surfactant concentrations. In Fig.6, $C_{\mathrm{V}}$ value of the St polymerization with SOS increased with $C_{\mathrm{S}}$ in the range above the $\mathrm{CMC}$, and the $C_{\mathrm{V}}$ increase was gradual in comparison with the one 
with SDS around its CMC.

In Fig. 5 , the bending point of the $N_{\mathrm{p}}$ curve for $X_{\mathrm{MMA}}=0.5$ with SOS is not clearly seen. It was reported that polymerization of monomers with a high solubility to water solvent tended to lose a bending point for the number of polymer particles plotted against surfactant concentration [42].

Nomura et al. reported that the Smith-Ewart theory was not applicable to the emulsion copolymerization of St and MMA with SDS and potassium persulfate (KPS) because of desorption of radicals from polymer particles and surfactant micelles $[43,45]$. In their reports, the slope of $N_{\mathrm{p}}$ curve at $X_{\mathrm{MMA}}=0.51$ was 0.76 , with $N_{\mathrm{p}}$ value approximately 1.5 times higher than that at $X_{\mathrm{MMA}}=0$ [43]. The present polymerizations with SOS have a tendency of $N_{\mathrm{p}}$ similar to those reported by Nomura et al..

In Fig.6, $C_{\mathrm{V}}$ for $X_{\mathrm{MMA}}=0.5$ with SOS increases with $C_{\mathrm{S}}$ and its slope above the CMC is most moderate among the three polymerizations. This suggests transition from the homogeneous nucleation to heterogeneous nucleation. Since large numbers of particles were produced for $X_{\mathrm{MMA}}$ $=0.5$ with SOS in Fig.5, it can be expected that the generation of polymer particles quickly reduces actual surfactant concentration in the water phase.

The equilibrium isotherms of surfactant adsorption onto polymer particles were reported for a variety of normal sodium alkyl sulfates $\left(\mathrm{C}_{n} \mathrm{H}_{2 n+1} \mathrm{SO}_{4} \mathrm{Na}\right)$ [44], providing the area $\left(A_{\mathrm{m}}\right)$ occupied by a surfactant at saturation adsorption to polymer particles. Using the $A_{\mathrm{m}}$ of normal sodium alkyl sulfates, the particle size of micelle disappearance, $d_{\mathrm{m}}$, in the present polymerizations are estimated under the assumption of monodispersity for particles sizes (also see electronic supplementary 
material for detailed calculation procedure). The calculated values of $d_{\mathrm{m}}$ for SOS were less than $7.6 \mathrm{~nm}$ for the copolymerizations of St and MMA at $[\mathrm{SOS}] \leqq 1.0 \mathrm{mM}$, whereas those for SOS were less than $6.0 \mathrm{~nm}$ for the St polymerizations at $[\mathrm{SOS}] \leqq 0.2 \mathrm{mM}$. The low values of $d_{\mathrm{m}}$ suggest that the micelles disappeared in a very early stage of the polymerization. The polymer yield corresponding to the micelle disappearance was $1 \%$ at most in the present polymerizations.

The surface coverage of PSt particles with SDS was reported for conventional emulsion polymerization that was conducted at various St concentrations for $[\mathrm{SDS}]=40 \mathrm{mM}$ with KPS initiator [48]. In the polymerization experiments, the saturated adsorption, corresponding to the surface coverage $(\theta)=1$, was maintained until the completion of polymerization at $[\mathrm{St}] \leqq 96.4$ $\mathrm{g} / \mathrm{dm}^{3}$. In this range of monomer concentration, the existence of micelles generated new particles until the end of polymerization, and the number of polymer particles increased with St concentration. If we calculate $d_{\mathrm{m}}$ for $N_{\mathrm{p}}=4.8 \times 10^{20} \mathrm{~m}^{-3}$ of the polymerization, which was conducted at $[\mathrm{St}]=0.36 \mathrm{M}\left(37.9 \mathrm{~g} / \mathrm{dm}^{3}\right)$ similar to our case of $0.3 \mathrm{M} \mathrm{St}$, the use of the $A_{\mathrm{m}}(0.42$ $\mathrm{nm}^{2}$ ) in the report [48] indicates a large value of $d_{\mathrm{m}}=75 \mathrm{~nm}$. This datum is further applied to the confirmation of the small $d_{\mathrm{m}}$ in the present polymerization. For instance, the $d_{\mathrm{m}}$ for PSt particles at $[\mathrm{SOS}]=0.2 \mathrm{mM}$, estimated with the relation of $\left[\frac{d_{\mathrm{m}}^{2} N_{\mathrm{P}}}{A_{\mathrm{m}}\left(C_{\mathrm{s}}-\mathrm{CMC}\right)}\right]_{\mathrm{SDS}}=\left[\frac{d_{\mathrm{m}}^{2} N_{\mathrm{P}}}{A_{\mathrm{m}}\left(C_{\mathrm{s}}-\mathrm{CMC}\right)}\right]_{\mathrm{SOS}}$, is less than 8 $\mathrm{nm}$ because the $A_{\mathrm{m}}$ of SOS is smaller than the one of SDS. It is clear that the small $d_{\mathrm{m}}$ in the present polymerization is mainly due to the low surfactant concentration.

Since the present method generates particles in the presence of micelles and complete the generation for a very early period, it could have features of emulsion polymerization for large 
number production and of soap-free emulsion polymerization for high monodispersity in particle sizes. With the features, the present work could produce monodisperse polymer particles with $d_{\mathrm{V}}$ $=33 \mathrm{~nm} . \quad$ The process is environmentally adaptable and different from conventional emulsion polymerization conducted at high surfactant concentrations. 


\section{Conclusions}

A long alkyl chain surfactant of SOS with a low CMC was employed in emulsion copolymerization of hydrophobic St and less hydrophobic MMA initiated by APS. The polymerization ranged surfactant concentration, initiator concentration and monomer ratio at a total monomer concentration of $0.3 \mathrm{M}$. An increase in MMA mole fraction in the copolymerization $\left(X_{\mathrm{MMA}}\right)$ increased the number of polymer particles, while the particle dispersion was destabilized at $X_{\mathrm{MMA}} \geqq 2 / 3$. The polymerizations conducted for $X_{\mathrm{MMA}}=0.5$ at APS concentrations of 10 and 20 $\mathrm{mM}$ indicated that the latter APS concentration allowed the favorable results of large $N_{\mathrm{p}}$ and small $C_{\mathrm{V}}$. The CMC of SOS was reduced to $0.085 \mathrm{mM}$ by the addition of APS at the high concentration of $20 \mathrm{mM}$. SOS concentration was ranged across the CMC in emulsion polymerization at the APS concentration of $20 \mathrm{mM}$ for $X_{\mathrm{MMA}}=0$ and 0.5 . In the both cases of $X_{\mathrm{MMA}}$, monodisperse polymer nanoparticles could be produced at surfactant concentrations well above the $\mathrm{CMC}$, which is a distinctive feature different from conventional emulsion polymerization producing polydisperse particles at surfactant concentrations above CMC. The present results imply that the low CMC enables the production of large number of polymer particles in the presence of micelles even at low surfactant concentrations and the completion of particle generation in a very early stage of the polymerization. The reaction conditions of $X_{\mathrm{MMA}}=0.5$ and $1 \mathrm{mM}$ SOS prepared monodisperse polymer particles with $d_{\mathrm{V}}$ as small as $33 \mathrm{~nm}$. 


\section{Acknowledgement}

This research was mainly supported by the Ministry of Education, Culture, Sports, Science and Technology (JSPS KAKENHI Grant No. 25600001). This research was partially supported by the Adaptable and Seamless Technology transfer Program through target driven R\&D (A-STEP) from Japan Science and Technology Agency, JST (Grant No. AS262Z02259M).

\section{Figure Captions}

Table Averaged diameters $\left(d_{\mathrm{v}}\right)$, coefficients of variation of particle size distribution $\left(C_{\mathrm{v}}\right)$, polydispersity index $\left(d_{\mathrm{w}} / d_{\mathrm{n}}\right)$, hydrodynamic diameters $\left(d_{\mathrm{DLS}}\right)$, polydispersity index $\left(\mathrm{PDI}_{\mathrm{DLS}}\right)$ calculated from DLS measurement, the final numbers of particles $\left(N_{\mathrm{p}}\right)$, polymer yields and solid contents (SC) in polymerizations in the presence of SOS.

Figure 1 Schematic illustration on the proposed method using a combination of hydrophobic and less hydrophobic monomers. Sodium octadecylsulfate (SOS) was employed as an anionic surfactant with a low CMC.

Figure 2 (a) SEM image of polymer nanoparticles prepared in the emulsion polymerization of $\operatorname{MMA}\left(X_{\mathrm{MMA}}=1.0\right)$. (b) Averaged diameters $\left(d_{\mathrm{v}}\right)$ and coefficients of variation of particle size distribution $\left(C_{\mathrm{v}}\right)$ plotted against MMA molar composition in monomer (St + MMA). The concentrations of monomer, SOS and APS were $0.3 \mathrm{M}, 0.1 \mathrm{mM}$ and $20 \mathrm{mM}$, respectively.

Figure 3 TEM images of polymer nanoparticles prepared by emulsion polymerization of St in the SOS concentration range of $0.025-1.0 \mathrm{mM}$. The concentrations of St and APS were $0.3 \mathrm{M}$ and 20 $\mathrm{mM}$, respectively. Each scale bar shows $200 \mathrm{~nm}$. 
Figure 4 TEM images of polymer nanoparticles prepared by emulsion copolymerization of St and $\operatorname{MMA}\left(X_{\mathrm{MMA}}=0.5\right)$ in the SOS concentration range of $0.05-1.0 \mathrm{mM}$. The concentrations of St, MMA and APS were 0.15 M, 0.15 M and $20 \mathrm{mM}$, respectively. Each scale bar shows $100 \mathrm{~nm}$.

Figure 5 The number of particles, $N_{\mathrm{p}}$, plotted against surfactant concentration, $C_{\mathrm{s}}$. Closed triangle shows results in the emulsion polymerization of St in the presence of SOS. Closed and open circles show results in the emulsion copolymerization $\left(X_{\mathrm{MMA}}=0.5\right)$ in the presence of SOS and SDS, respectively. Monomer and APS concentrations were $0.3 \mathrm{M}$ and $20 \mathrm{mM}$, respectively.

Figure 6 Coefficient of variation, $C_{\mathrm{V}}$, plotted against surfactant concentration, $C_{\mathrm{s}}$. Closed triangle shows results in the emulsion polymerization of St in the presence of SOS. Closed and open circles show results in the emulsion copolymerization $\left(X_{\mathrm{MMA}}=0.5\right)$ in the presence of SOS and SDS, respectively. Monomer and APS concentrations were $0.3 \mathrm{M}$ and $20 \mathrm{mM}$, respectively. 


\section{References}

1. Bellamine, A.; Degrandi, E.; Gerst, M.; Stark, R.; Beyers, C.; Creton, C. Macromol. Mater. Eng. 2011, 296, 31-41.

2. $\quad$ England, D.; Tambe, N.; Texter, J. ACS Macro Lett. 2012, 1, 310-314.

3. Seijo, B.; Fattal, E.; Roblot-Treupel, L.; Couvreur, P. Int. J. Pharm. 1990, 62, 1-7.

4. Nandiyanto, A. B. D.; Akane, Y.; Ogi, T.; Okuyama, K. Langmuir 2012, 28, 8616-8624.

5. Antonietti, M. Adv. Mater. 1998, 10, 154-159.

6. Zhang L.; Wang, H.; Zhang, Z.; Qin, F.; Liu, W.; Song, Z. Applied Surface Sci. 2011, 258, $1217-1224$.

7. Yuan, J.; Zhou, T.; Pu, H. J. Phys. Chem. Solids 2010, 71, 1013-1019.

8. Nandiyanto, A. B. D.; Suhendi, A.; Y.; Ogi, T.; Iwaki, T.; Okuyama, K. Colloids surf. A: Physicochem. Eng. Aspects 2012, 396, 96-105.

9. Rao, J. P.; Geckeler, K. E. Progress in Polym. Sci. 2011, 36, 887-913.

10. Wang, W.; Liu, H.; Hu, X.; Yi, C.; Wu, S.; Chu, K P; Xu, Z. Polym. Int. 2011, 60, 1638-1645.

11. Kohri, M.; Kobayashi, A; Fukushima, H.; Kojima, T.; Taniguchi, T.; Saito, K.; Nakahira, T. Polym. Chem. 2012, 3, 900-906.

12. Harkins, W.D. J. Am. Chem.Soc. 1947, 69, 1428-1444.

13. Smith, W.D..; Ewart, R. H. J. Chem. Phys. 1948, 16, 592-599. 
14. Roe, C.P. Ind. Eng. Chem. 1968, 60, 20-33.

15. Nunes, J. S.; Asua, J. M. Langmuir 2013, 29, 3895-3902.

16. Sajjadi, S. J. Colloid Interf. Sci.2015, 445, 174-182.

17. Atik, S. S.; Thomas, J. K. J. Am. Chem. Soc. 1981, 103, 4279-4280.

18. Guo, S. J.; El-Aasser, S. M.; Vanderhoff, W. J. J. Polym. Sci.: Part A: Polym. Chem. 1989, 27, $691-710$

19. Candau, F. In Polymeric Dispersions: Principles and Applications; J. M. Asua Eds.; Kluwer Academic Publishers: Dordrecht, 1997; p 127-140.

20. Landfester, K.; Bechthold, N.; Tiarks, F.; Antonietti, M. Macromolucules 1999, 32, $5222-5228$

21. Landfester, K. Macromol. Rapid Commun. 2001, 22, 896-936.

22. Schork, J. F.; Luo, Y.; Smulders, W.; Russum, J. P.; Butte, A.; Fontenot, K. Adv. Polym. Sci. $2005,175,129-255$

23. Fitch, R.M.; Tsai, C.H. In Polymer Colloids; Fitch, R. M., Eds.; Plenum Press: New York, 1971; p 73-102.

24. Arai, M.; Arai, K.; Saito, S. J. Polym. Sci. 1979, 17, 3655-3665.

25. Goodall, A.R.; Wilkinson, M.C.; Hearn, J. In Polymer Colloids II; Fitch, R. M., Eds.; Plenum Press: New York, 1980; p 629-650. 
26. Song, Z.; Poehlein, G. W. J. Colloid Interf. Sci. 1999, 128, 486-500.

27. Camli, S. T.; Buyukserin, F.; Balci, O.; Budak, G. G. J. Colloid Interf. Sci. 2010, 344, $528-532$.

28. Goodwin, J. W.; Hearn, J.; Ho, C. C.; Ottewill, R. H. Colloid Polym. Sci. 1974, 252, 464-471.

29. Goodwin, J. W.; Ottewill, R. H.; Pelton, R. Colloid Polym. Sci. 1979, 257, 61-69.

30. Hearn, J. J. Polym. Sci. 1985, 23, 1869-1883.

31. Shouldice, G. T. D.; Vandezande, G. A.; Rudin, A. Eur.Polym. J. 1994, 30, 179-183.

32. Gu, S.; Inukai, S.; Konno, M. J. Chem. Eng. Jpn. 2002, 35, 977-981.

33. Gu, S.; Akama, H.; Nagao, D.; Kobayashi, Y.; Konno, M. Langmuir 2004, 20, 7948-7951.

34. Yamada, Y.; Sakamoto, T.; Gu.,S.; Konno, M. J. Colloid Interf. Sci. 2005, 281, 249-252.

35. Shibuya, K.; Nagao, D.; Ishii, H.; Konno, M. Polymer 2014, 55, 535-539.

36. Konno, M.; Terunuma, Y.; Saito, S. J. Chem. Eng. Jpn. 1991, 24, 429-437.

37. Tauer, K. In Colloids and Colloid Assemblies; Caruso, F., Eds.; Wiley-VCH Verlag GmbH \& Co. KGaA: Weinheim, 2004; ch. 1.

38. Kong, X. Z.; Zhu, X.; Jiang, X.; Li, X. Polymer 2009, 50, 4220-4227.

39. Zhendxing, H.; Xiaowei, Y.; Junliang, L.; Yuping, Y.; Ling, W.; Yanwei, Z. Eur. Polym. J. 2011, 47, 24-30.

40. Arunbabu, D.; Jana, T. J. Colloid Interf. Sci. 2011, 361, 534-542. 
41. Ishii, H.; Ishii, M.; Nagao, D.; Konno, M. Polymer 2014, 55, 2772-2779.

42. Sütterlin, N. In Polymer Colloids II; Fitch, R. M., Eds.; Plenum Press: New York, 1980; p 583-597.

43. Nomura, M.; Horie, I.; M. Kubo, Fujita, K. J. Appl. Polym. Sci. 1989, 37, 1029-1050.

44. Piirma, I.; Chen, S.-R. J. Colloid Interf. Sci. 1980, 74, 90-102.

45. Nomura, M.; Yamamoto, K.; Horie, I.; Fujita, K.; Harada, M. J. Appl. Polym. Sci. 1982, 27, 2783-2501.

46. Krishnan, S.; Klein, A.; El-Aasser, M. S.; Sudol, E. D. Macromolecules 2003, 36, 3152-3159.

47. Fitch, R. M. In Polymer colloids: A Comprehensive Introduction; Academic Press: London, 1997; ch. 2.

48. Varela, L; Rosa, D.-L.; Sudol, D. E.; El-Aasser, S.; Klein, A. J. Polym. Sci.: Part A: Polym. Chem. 1999, 37, 4073-4089. 
Graphical Abstract

\section{Emulsion copolymerization of St and MMA}

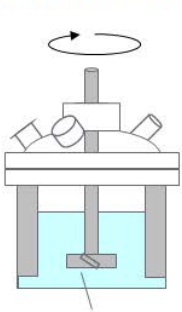
with a low CMC surfactant

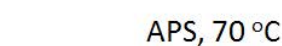

Sodium Octadecyl Sulfate (SOS)

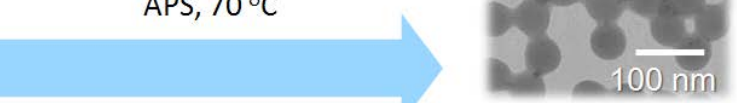

[Surfactant] $<0.04$ wt\% $(\mathrm{CMC}=0.085 \mathrm{mM})$

$d_{\mathrm{v}}=48 \mathrm{~nm}$

$c_{\mathrm{v}}=6.5 \%$

$[\mathrm{SOS}]=1.0 \mathrm{mM}$

$d_{\mathrm{v}}=33 \mathrm{~nm}$

$C_{\mathrm{V}}=9.2 \%$ 
$\underline{\text { Table }}$

Table Averaged diameters $\left(d_{\mathrm{v}}\right)$, coefficients of variation of particle size distribution $\left(C_{\mathrm{v}}\right)$, polydispersity index $\left(d_{\mathrm{w}} / d_{\mathrm{n}}\right)$, hydrodynamic diameters $\left(d_{\mathrm{DLS}}\right)$, polydispersity index (PDI $\left.\mathrm{PLS}\right)$ calculated from DLS measurement, the final numbers of particles $\left(N_{\mathrm{p}}\right)$, polymer yields, and solid contents (SC) in polymerizations in the presence of SOS.

\begin{tabular}{|c|c|c|c|c|c|c|c|c|c|c|c|}
\hline Run & $\begin{array}{c}\text { St } \\
{[\mathbf{M}]}\end{array}$ & $\begin{array}{c}\text { MMA } \\
{[\mathbf{M}]}\end{array}$ & $\begin{array}{c}\text { SOS } \\
{[\mathrm{mM}]}\end{array}$ & $\begin{array}{c}d_{V} \\
{[\mathrm{~nm}]}\end{array}$ & $\begin{array}{c}C_{\mathrm{V}} \\
{[\%]}\end{array}$ & $\begin{array}{c}d_{\mathrm{w}} / d_{\mathrm{n}} \\
{[-]}\end{array}$ & $\begin{array}{c}d_{\text {DLS }} \\
{[\mathrm{nm}]}\end{array}$ & $\begin{array}{c}\text { PDI }_{\text {DLS }} \\
{[-]}\end{array}$ & $\begin{array}{c}N_{\mathrm{P}} \\
{\left[\mathrm{m}^{-3}\right]}\end{array}$ & $\begin{array}{c}\text { Yield } \\
{[\%]}\end{array}$ & $\begin{array}{c}\text { SC } \\
{[\mathrm{wt} \%]}\end{array}$ \\
\hline 1 & 0.3 & - & 0.025 & 218 & 1.9 & 1.001 & 221 & 0.114 & $4.45 \times 10^{18}$ & 89 & 3.12 \\
\hline 2 & 0.3 & - & 0.05 & 165 & 2.0 & 1.001 & 185 & 0.021 & $1.01 \times 10^{19}$ & 88 & 3.10 \\
\hline 3 & 0.3 & - & 0.1 & 105 & 2.6 & 1.002 & 116 & 0.013 & $4.01 \times 10^{19}$ & 89 & 3.12 \\
\hline 4 & 0.3 & - & 0.15 & 74 & 8.9 & 1.023 & 81 & 0.018 & $1.05 \times 10^{20}$ & 82 & 2.93 \\
\hline 5 & 0.3 & - & 0.2 & 67 & 8.4 & 1.019 & 75 & 0.014 & $1.59 \times 10^{20}$ & 91 & 3.18 \\
\hline 6 & 0.3 & - & 0.4 & 58 & 12.3 & 1.042 & 64 & 0.011 & $2.42 \times 10^{20}$ & 92 & 3.21 \\
\hline 7 & 0.3 & - & 1.0 & 46 & 13.1 & 1.047 & 50 & 0.082 & $4.22 \times 10^{20}$ & 99 & 3.48 \\
\hline 8 & 0.2 & 0.1 & 0.1 & 75 & 2.8 & 1.002 & 82 & 0.009 & $1.17 \times 10^{20}$ & 95 & 3.29 \\
\hline 9 & 0.1 & 0.2 & 0.1 & 60 & 4.1 & 1.005 & Coagulation & - & - & - & - \\
\hline 10 & 0 & 0.3 & 0.1 & - & - & - & Coagulation & - & - & - & - \\
\hline 11 & 0.15 & 0.15 & 0.05 & 74 & 3.4 & 1.004 & 110 & 0.066 & $1.02 \times 10^{20}$ & 80 & 2.83 \\
\hline 12 & 0.15 & 0.15 & 0.1 & 64 & 3.8 & 1.004 & 80 & 0.007 & $1.80 \times 10^{20}$ & 94 & 3.20 \\
\hline 13 & 0.15 & 0.15 & 0.15 & 56 & 4.5 & 1.006 & 71 & 0.011 & $2.70 \times 10^{20}$ & 92 & 3.17 \\
\hline 14 & 0.15 & 0.15 & 0.2 & 51 & 4.6 & 1.007 & 63 & 0.011 & $3.28 \times 10^{20}$ & 87 & 3.02 \\
\hline 15 & 0.15 & 0.15 & 0.4 & 48 & 6.5 & 1.013 & 57 & 0.028 & $4.26 \times 10^{20}$ & 92 & 3.17 \\
\hline 16 & 0.15 & 0.15 & 1.0 & 33 & 9.2 & 1.026 & 43 & 0.069 & $1.34 \times 10^{21}$ & 97 & 3.35 \\
\hline 17 & 0.15 & 0.15 & 2.0 & 33 & 12.1 & 1.041 & 37 & 0.054 & $1.15 \times 10^{21}$ & 87 & 3.08 \\
\hline
\end{tabular}

The polymerizations were conducted at the APS concentration of $20 \mathrm{mM}$ and $70{ }^{\circ} \mathrm{C}$. 

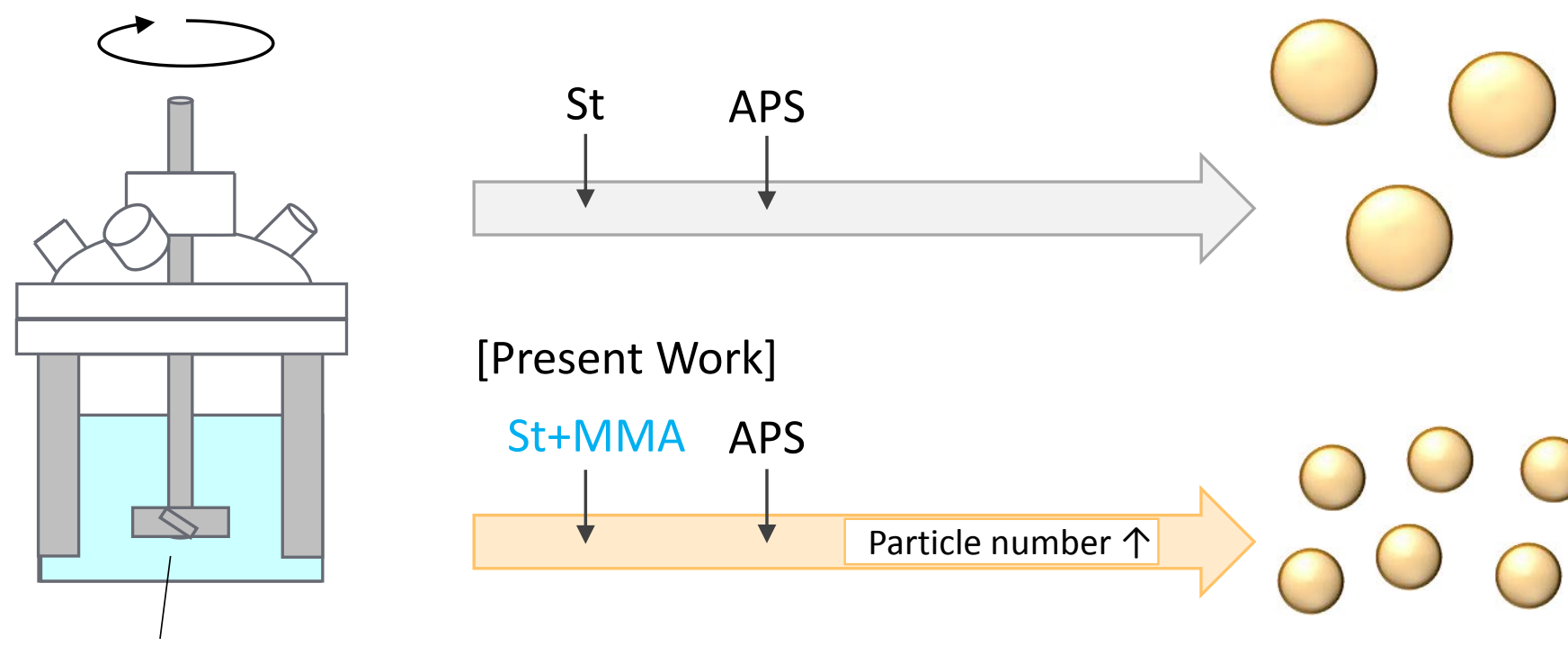

Sub- $100 \mathrm{~nm}$ Monodisperse Latices

\section{[Present Work]}

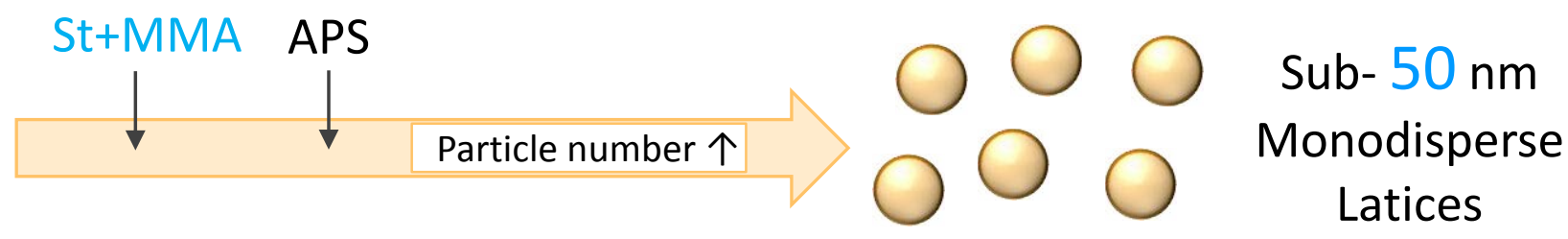

$[\mathrm{SOS}]<0.04 \mathrm{wt} \%$

Figure 1 Schematic illustration on the proposed method using a combination of hydrophobic and less hydrophobic monomers. Sodium octadecylsulfate (SOS) was employed as an anionic surfactant with a low CMC 

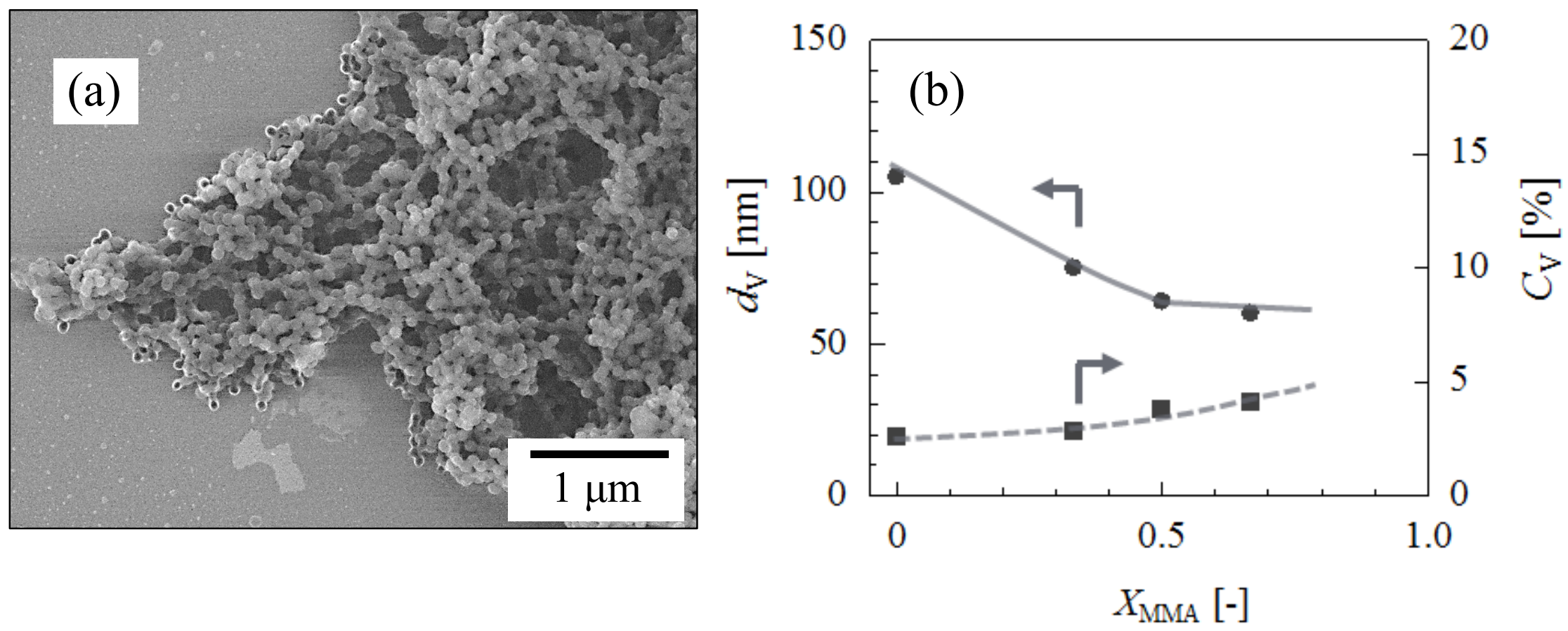

Figure 2 (a) SEM image of polymer nanoparticles prepared in the emulsion polymerization of MMA $\left(X_{\mathrm{MMA}}=1.0\right)$. (b) Averaged diameters $\left(d_{\mathrm{v}}\right)$ and coefficients of variation of particle size distribution $\left(C_{\mathrm{v}}\right)$ plotted against MMA molar composition in monomer (St $\left.+\mathrm{MMA}\right)$. The concentrations of monomer, SOS and APS were $0.3 \mathrm{M}, 0.1 \mathrm{mM}$ and $20 \mathrm{mM}$, respectively. 

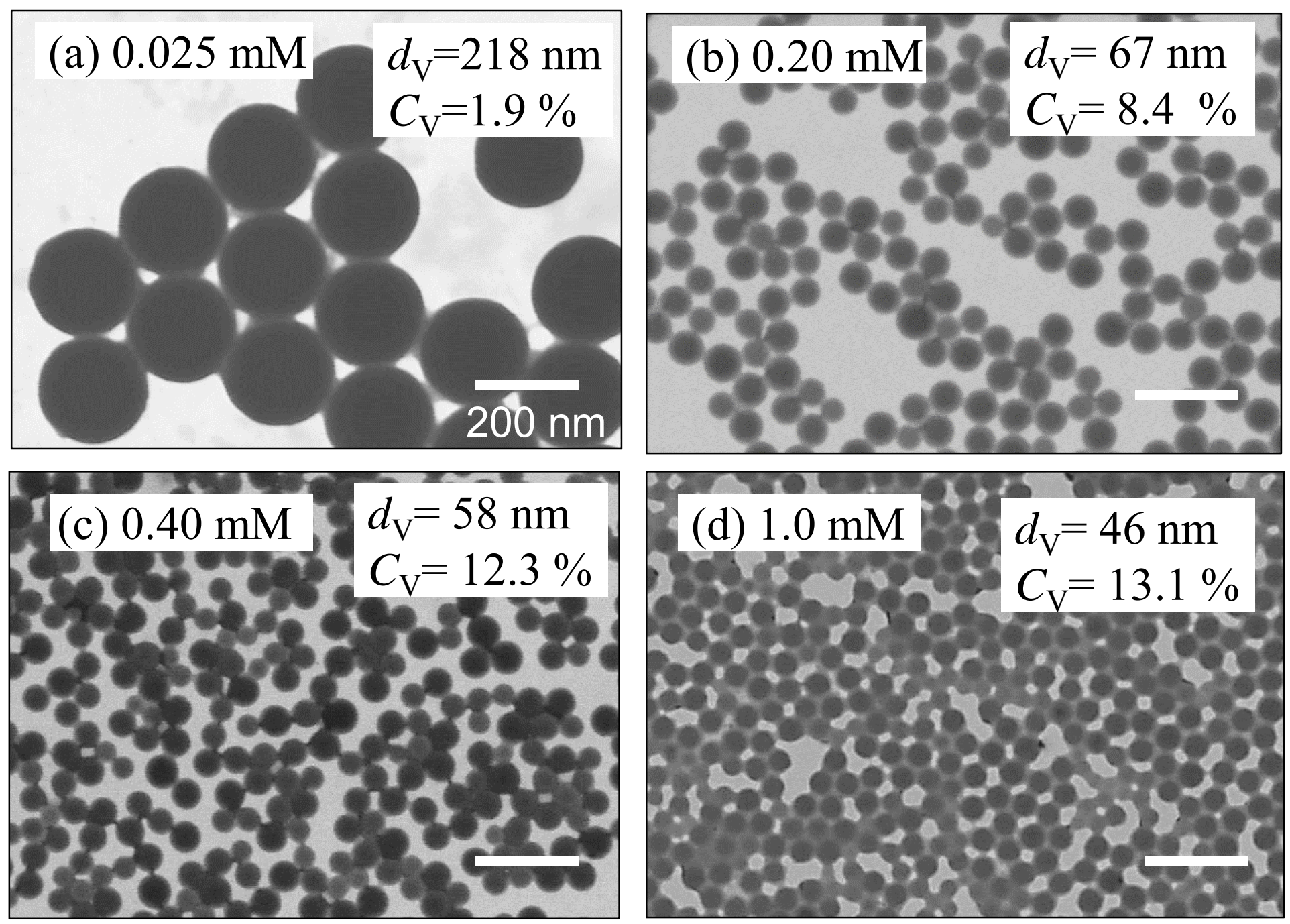

Figure 3 TEM images of polymer nanoparticles prepared by emulsion polymerization of $\mathrm{St}$ in the SOS concentration range of $0.025-1.0$ $\mathrm{mM}$. The concentrations of St and APS were $0.3 \mathrm{M}$ and $20 \mathrm{mM}$, respectively. Each scale bar shows $200 \mathrm{~nm}$. 

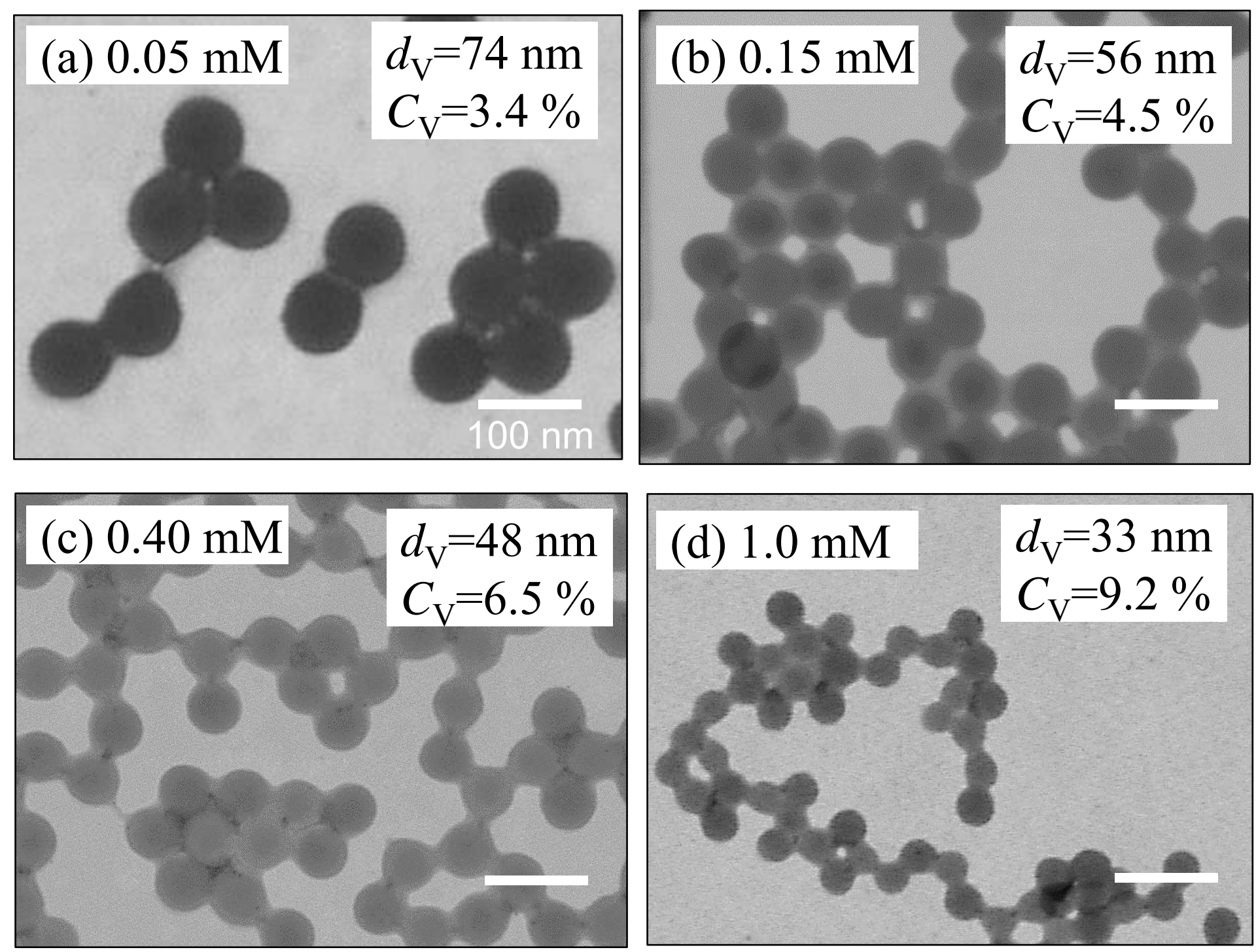

Figure 4 TEM images of polymer nanoparticles prepared by emulsion copolymerization of St and MMA $\left(X_{\mathrm{MMA}}=0.5\right)$ in the SOS concentration range of $0.05-1.0 \mathrm{mM}$. The concentrations of St, MMA and APS were $0.15 \mathrm{M}, 0.15 \mathrm{M}$ and $20 \mathrm{mM}$, respectively. Each scale bar shows $100 \mathrm{~nm}$. 


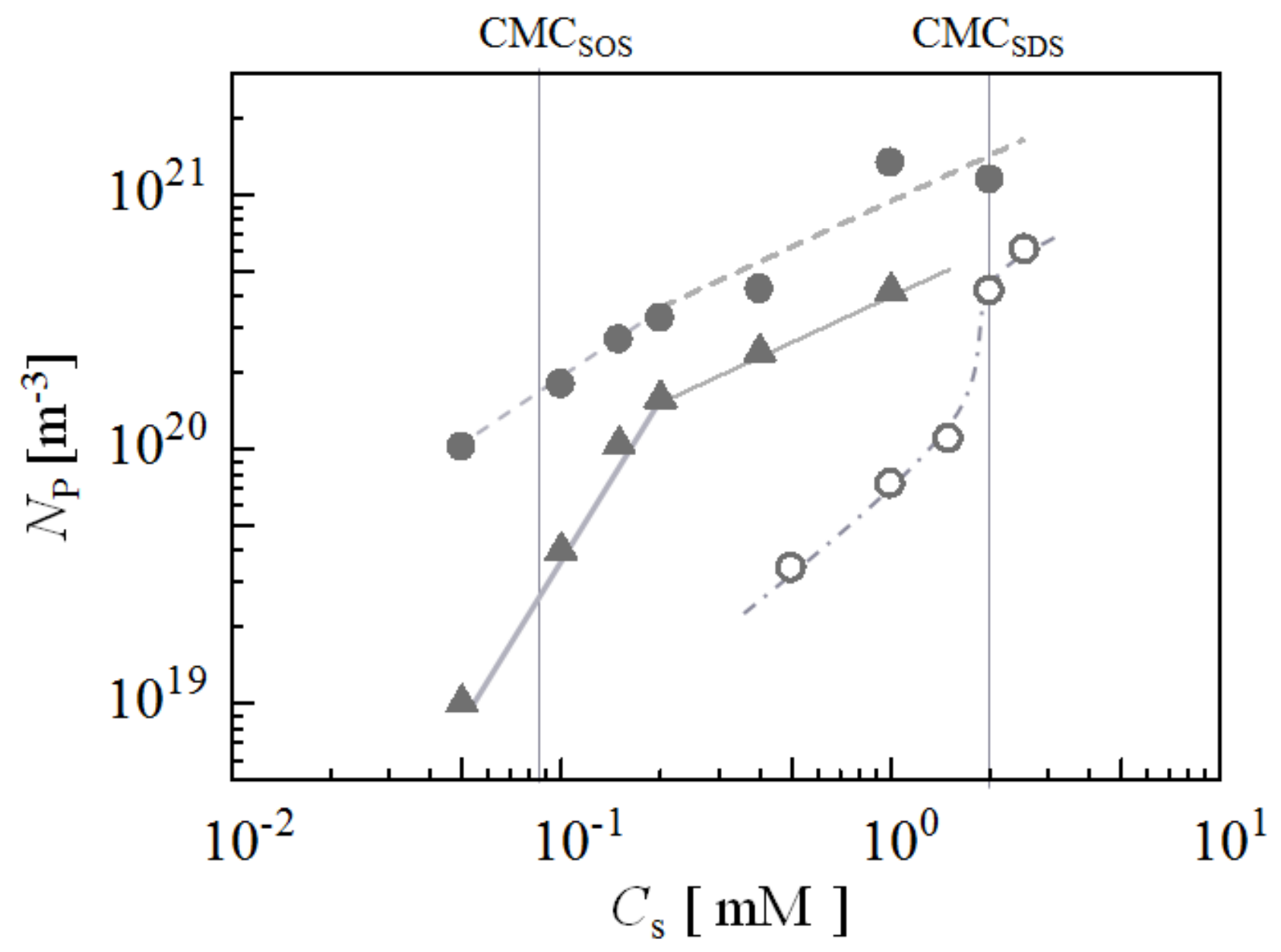

Figure 5 The number of particles, $N_{\mathrm{p}}$, plotted against surfactant concentration, $C_{\mathrm{s}}$. Closed triangle shows results in the emulsion polymerization of $\mathrm{St}$ in the presence of SOS. Closed and open circles show results in the emulsion copolymerization $\left(X_{\mathrm{MMA}}=0.5\right)$ in the presence of SOS and SDS, respectively. Monomer and APS concentrations were $0.3 \mathrm{M}$ and $20 \mathrm{mM}$, respectively. 


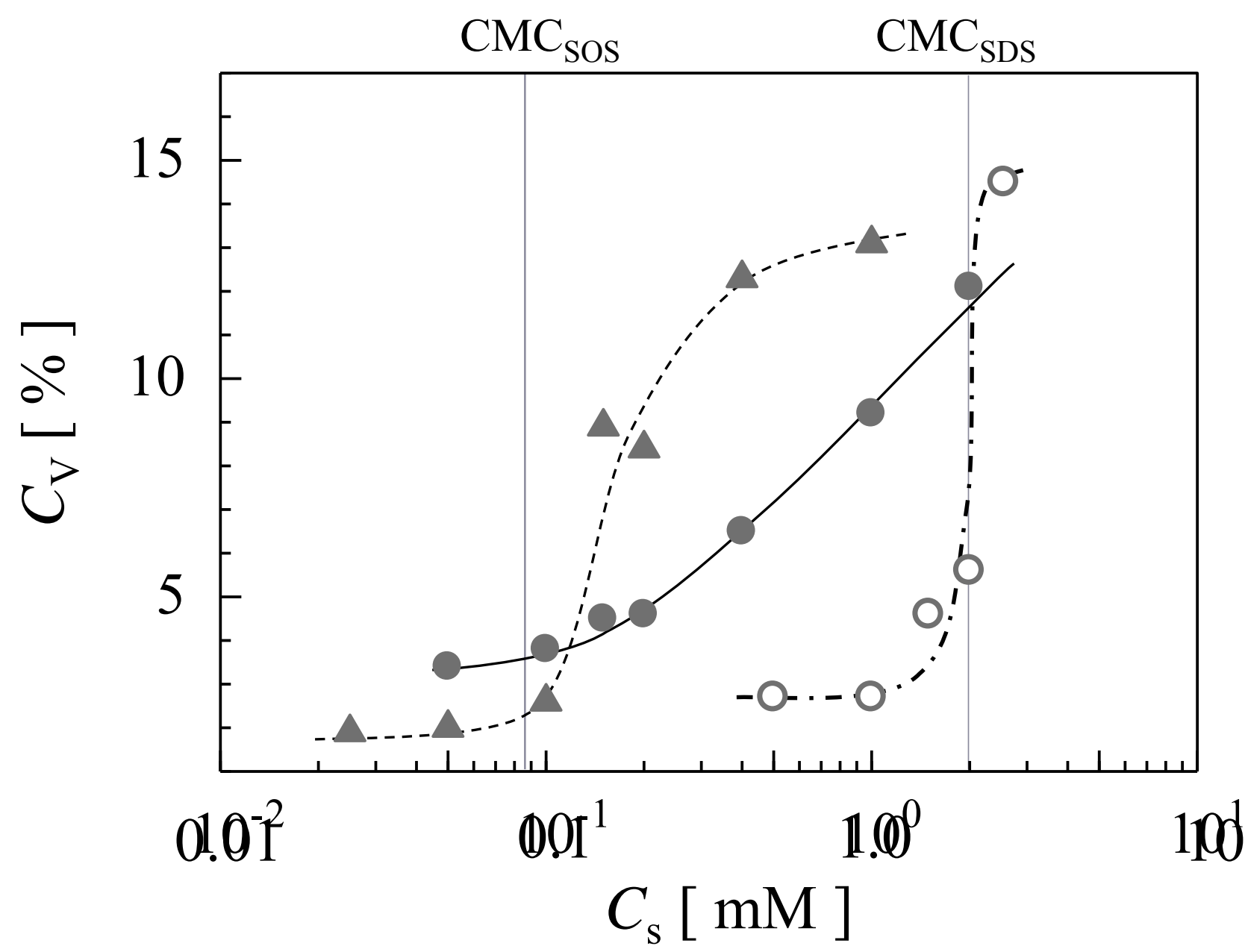

SOS-St $_{\text {MMA }}$
SOS-St
SDS-St $_{\text {MMA }}$

Figure 6 Coefficient of variation, $C_{\mathrm{V}}$, plotted against surfactant concentration, $C_{\mathrm{s}}$. Closed triangle shows results in the emulsion polymerization of St in the presence of SOS. Closed and open circles show results in the emulsion copolymerization $\left(X_{\mathrm{MMA}}=0.5\right)$ in the presence of SOS and SDS, respectively. Monomer and APS concentrations were $0.3 \mathrm{M}$ and $20 \mathrm{mM}$, respectively. 